sections provide numerous additional references for those requiring further information. The book should be on the library shelves of any researchers, government agencies and non-government conservation and scientific organizations studying seabird biology and/ or the conservation of seabirds. Errors appear to be few - the reference to Wilson et al. (1985) cited on page 116 is not listed in that chapter's literature cited section, which includes two references that don't appear to have been cited. However, since most of the chapters are written as scientific papers, some may be too technical for some readers. The review by Cooper et al. of legal and quasilegal aspects of the issue provides a valuable reference compendium, but is so riddled with acronyms that I found myself wishing for a glossary. I also hope that the seven abstracts at the end of the book are expanded into full papers somewhere. As valuable a contribution as the book is in itself, this volume will undoubtedly also stimulate more research

\section{The Life of Mammals}

By David Attenborough. 2002. Princeton University Press, New Jersey. 320 pages, U.S.\$29.95.

As the latest edition in the BBC "Life" series combining television and print media, the book on mammals is nicely illustrated with a good selection of colour photographs that closely follows the engaging text by David Attenborough as he presents interesting stories on these fascinating animals. The first chapter, "A Winning Design", starts off with the ability of mammals to adapt to different environments on earth, including the harsh arctic conditions where lemmings live year round. After describing some basic characters of mammals, such as hair and the production of milk, there is a general introduction to the origin and evolution of this group of warm-blooded organisms. The chapter finishes off with two early mammalian radiations that cover the egg-laying monotremes and the marsupials, which give birth to under-developed young.

The remaining nine chapters deal with the placental eutherian mammals but instead of continuing to describe them by scientific groups the format switches to artificial categories such as diet and habitat. This unnatural classification seems awkward at times with bats, which people can readily identify with, split into two separate chapters, "Insect Hunters" (curiously including vampire bats) and "Life in the Trees" (although some insect-eating bats also live in trees). There was a missed opportunity to educate readers in scientific classification and evolution while still entertaining them with a plethora of amazing natural history stories.

Primates get star billing in the book with the last two and a half chapters devoted to this charismatic order of mammals. Although the higher-level taxonomy (or common names employed) is not current, it begins with prosimians as an early branch of the primates. The latest view is that this is not a natural group be- that will require another update before long. Such an update could usefully also include papers or chapters on aquatic bird bycatch of fisheries on inland waters, such as those of the Great Lakes, several large prairie province lakes and similar lakes on other continents.

MARTin K. MCNiCHOLL

4735 Canada Way, Burnaby, British Columbia V5G 1L3 Canada

cause, for example, tarsiers are more closely related to monkeys and apes, as alluded to but nonetheless still included in the chapter with lemurs. The other primates are grouped to cover the new and old world monkeys, and ending with the gibbons and great apes, including a branch for humans. The last half chapter concentrates on both physical and social anthropology from the first evidence of bipedal locomotion to cultivation and civilization.

The book is definitely aimed at a general but knowledgeable audience with an interest in nature and mammals. I am sure, however, that practising biologists will still find a few facts new to them in their nonspecialist group because the background research is relatively good. It was nice to see some recent scientific hypotheses on mammalian evolution making it into the book such as the close relationship between whales and hippopotamuses. But some other emerging ideas based primarily on molecular data did not, including the association of bats with carnivores, ungulates and whales, as opposed to insectivores, or tree shrews, flying lemurs and primates.

My criticisms are mostly biologically oriented because the book is attractively presented with most photographs of good quality and information well written. But there should be more books that combine current scientific research with an explanation of the deeper implications or processes involved for wider distribution to the general public looking for meaningful substance beyond the usual cursory facts.

BurTON K. LIM

Centre for Biodiversity and Conservation Biology, Royal Ontario Museum, 100 Queen's Park, Toronto, Ontario M5S 2C6 Canada

Geographic Variation in Size and Shape of 


\section{Savannah Sparrows (Passerculus sandwichensis)}

By James D. Rising. 2001. Studies in Avian Biology Number 23. Cooper Ornithological Society, Camarillo, California. 65 pages. U.S.\$7.
The newer field guides, such as The Sibley Guide to Birds, occasionally describe and illustrate subspecies of birds, usually based on differences in plumage or

soft parts. The "bander's bible", Peter Pyle's Identification Guide to North American Birds, includes wing and

tail measurements to help banders identify birds to the subspecies level - for example, he discusses 14 subspecies of the Savannah Sparrow. But have you ever wondered why these differences exist in the natural world?

Rising does and asks two questions in this regard: Why do features such as body size, wing length, or bill size and shape differ across a species' range? and, if these differences reflect adaptations to the different environments to which the species is exposed, what are the selective factors that have caused them?

One of the classic explanations for geographic variation in size is Bergmann's Rule, which holds that individuals of a species (vertebrates only) from colder areas are generally larger-bodied than individuals from warmer areas. Allen's Rule takes this one step further, stating that within such species, individuals from colder areas will have smaller appendages relative to their body size than individuals from warmer areas.

Rising asked his questions of the Savannah Sparrow, which is one of the most wide-spread songbirds in North America. He describes and quantifies geographic variation in the species throughout its breeding range, from Alaska to the Maritimes to central Mexico, and relates trends in phenotypic variation to environmental variation.

He found some clinal variation in size of Savannah Sparrows, with birds from the northeast being slightly larger than those from the west, and birds in cool, moist areas were larger than those where it is hot and dry. But the species overall did not seem to follow Bergmann's Rule; rather, measures of summer temperature and precipitation explained well the patterns of size variation. His more significant find, though, was that birds were larger on islands than on mainland sites, whether in the Aleutian Islands, Alaska, or on Sable Island, Nova Scotia. He speculates that the long, cool, moist summers on these islands results in a predictable and fairly rich food supply. This, combined with the rather long breeding season, allows multiple broods and perhaps enhanced competition for high quality territories. This competition for either food or territories might select for larger body size.

Rising ends with some taxonomic comments, coming out on the side of the "lumpers". He sees no virtue in naming subspecies where the only way they can be reliably separated is by locality. He suggests recognizing only two subspecies of non-saltmarsh Savannah Sparrows, $P$. s. sandwichensis (large size) and $P$. $s$. princeps (large and pallid), whereas the nine saltmarsh subspecies seem to be clearly separable by morphological characters. This is in contrast to the 17 subspecies currently recognized by the American Ornithologists' Union.

Rising's work relies on Principal Components and Discriminant Functions analyses, which, although I found it a little heavy going, was well presented sequentially and a good example of the use of these techniques for morphometric comparisons.

It will be interesting to watch in the coming years how Rising's thorough morphological studies interact with genetic analyses in assessing variation and the subspecies of Savannah Sparrows.

CYNDI M. SMITH

Box 5, Waterton Park, Alberta T0K 2M0 Canada

\section{Warblers of the Great Lakes and Eastern North America}

By Chris Early. 2003. Firefly Books Ltd., 3680 Victoria Park Avenue, Toronto, Ontario, M2H 3K1. 131 + pages. Cloth \$24.95: paper \$16.95

\section{Sparrows and Finches of the Great Lakes and Eastern North America}

By Chris Early. 2003. Firefly Books Ltd., 3680 Victoria Park Avenue, Toronto, Ontario, M2H 3K1. 128 + pages. Cloth \$24.95: paper \$.16.95

These books are an expansion and revision of two earlier books by Chris Early (Warblers of Ontario and Sparrows and Finches of Ontario). They both follow the successful format of the earlier books. Each species is shown in two to five photographs (Warblers) or two to seven photographs (Sparrows). The actual number of photographs for each species depends on how variable the bird's plumage can be. A short introductory note is followed by descriptions of the key 